Article

\title{
Optimal Dispatch of a Virtual Power Plant Considering Demand Response and Carbon Trading
}

\author{
Zuoyu Liu ${ }^{1}$, Weimin Zheng ${ }^{2}$, Feng Qi ${ }^{1}$, Lei Wang ${ }^{3}$, Bo Zou ${ }^{3}$, Fushuan Wen ${ }^{4,5, *(\mathbb{D})}$ and You Xue ${ }^{1}$ \\ 1 School of Electrical Engineering, Zhejiang University, No. 38 Zheda Rd., Hangzhou 310027, China; \\ liuzuoyu@zju.edu.cn (Z.L.); qifengzju@zju.edu.cn (F.Q.); xueyou@zju.edu.cn (Y.X.) \\ 2 State Grid Zhejiang Electric Power Co., Ltd., No. 8 Huanglong Rd., Hangzhou 310007, China; \\ zheng_weimin@zj.sgcc.com.cn \\ 3 State Grid Zhejiang Economic Research Institute, No.1 Nanfu Road, Hangzhou 310008, China; \\ wang_lei1@zj.sgcc.com.cn (L.W.); eebzou@zj.sgcc.com.cn (B.Z.) \\ 4 Department for Management of Science and Technology Development, Ton Duc Thang University, \\ Ho Chi Minh City, Vietnam \\ 5 Faculty of Electrical and Electronics Engineering, Ton Duc Thang University, Ho Chi Minh City, Vietnam \\ * Correspondence: fushuan.wen@tdt.edu.vn; Tel.: +84-837-755-037; Fax: +84-837-755-055
}

Received: 10 May 2018; Accepted: 5 June 2018; Published: 7 June 2018

check for updates

\begin{abstract}
The implementation of demand response (DR) could contribute to significant economic benefits meanwhile simultaneously enhancing the security of the concerned power system. A well-designed carbon emission trading mechanism provides an efficient way to achieve emission reduction targets. Given this background, a virtual power plant (VPP) including demand response resources, gas turbines, wind power and photovoltaics with participation in carbon emission trading is examined in this work, and an optimal dispatching model of the VPP presented. First, the carbon emission trading mechanism is briefly described, and the framework of optimal dispatching in the VPP discussed. Then, probabilistic models are utilized to address the uncertainties in the predicted generation outputs of wind power and photovoltaics. Demand side management (DSM) is next implemented by modeling flexible loads such as the chilled water thermal storage air conditioning systems (CSACSs) and electric vehicles (EVs). On this basis, a mixed integer linear programming (MILP) model for the optimal dispatching problem in the VPP is established, with an objective of maximizing the total profit of the VPP considering the costs of power generation and carbon emission trading as well as charging/discharging of EVs. Finally, the developed dispatching model is solved by the commercial CPLEX solver based on the YALMIP/MATLAB (version 8.4) toolbox, and sample examples are served for demonstrating the essential features of the proposed method.
\end{abstract}

Keywords: virtual power plant (VPP); demand response (DR); carbon trading mechanism; uncertainty; electric vehicle (EV)

\section{Introduction}

Power generation dominated by fossil fuels would result in environmental pollution deterioration and depletion of non-renewable resources. Clean renewable energy generation, which is typically available as distributed energy resources (DERs) [1], has been more and more exploited to mitigate the energy and environment crisis during the last two decades. Meanwhile, flexible loads have been widely employed to relieve the pressure brought by ever-growing demand for electricity. The increasing penetration of DERs and the growing diffusion of flexible loads are posing new challenges to the secure and economic operation of the concerned power systems, such as power output intermittency and fluctuations from weather-dependent distributed generators (DGs). In order to address the new 
challenges, the so-called virtual power plant (VPP) was proposed and has attracted much attention since then [2-4].

A VPP is a virtual entity which is aggregated by physical devices such as gas turbines, renewable energy units and flexible loads via advanced information technology and software systems [5], participating in the operation of the power system and electricity market concerned [6-8]. In the past few years, several VPP projects have been implemented worldwide, such as the European virtual fuel cell power plant [9] and the FENIX VPP [10]. In China, a VPP demonstration project has come into use in Yunnan Province, in southwest China [11].

Multiple kinds of benefits brought by a VPP have been addressed in some existing publications. In a VPP, appropriate management of energy storage systems (ESSs) [12] and electric vehicles (EVs) [13] could significantly contribute to the mitigation of the stochastic characteristics of DGs, thus enhancing the reliability of the energy system concerned. In addition, considerable profits could be gained by a VPP through participation in the well-established day-ahead electricity market [14,15], and the economic advantages are further demonstrated in [16-18] by presenting operating strategies for VPPs in day-ahead bidding and real-time multiple-period operation. Moreover, the demand response (DR) programs could be implemented. Flexible loads in a VPP could adjust their electrical consumption behaviors according to the electricity price and/or incentive mechanism. A DR program could not only bring economic benefits to the VPP and consumers [19,20] but also improve the load curve profile [21], while assuring meanwhile the required comfort levels of consumers [22].

On the other hand, renewable energy generating units and EVs aggregated by a VPP are beneficial to carbon emission reduction due to their inherent environmentally friendly features. Several methods are developed for addressing carbon emission problems in power system operation. The operating characteristics of carbon capture power plants (CCPPs) are analyzed in [23], and carbon emission constraints are integrated into the formulated dispatching optimization problem. The impacts of different carbon emission policies on the operation strategy of CCPPs are investigated in [24]. An optimization model of a collaborative power dispatching system with carbon emission trading included is developed in [25]. In [26], the effect of carbon emission trading on spinning reverse requirement of a low-carbon power system is analyzed. However, in existing publications, the environment benefits of a VPP have not yet been systematically examined, and will be examined in this paper.

To the best of our knowledge, the optimal dispatching problem of a VPP considering DR and participation in a carbon emission program under uncertain environment has not yet been systematically examined in existing related publications, and is the research focus of this work. The VPP aggregates gas turbines, wind power units, photovoltaic units, and flexible loads including EVs and chilled water thermal storage air conditioning systems (CSACS). Probabilistic models are employed to deal with uncertainties in the output predictions of intermittent renewable energy generation units. Demand side management (DSM) is next implemented by modeling CSACS and EVs. Then, a mixed integer linear programming (MILP) model for optimal dispatching considering carbon emission costs is proposed. Finally, the proposed model is solved by the commercial CPLEX solver based on the YALMIP toolbox in MATLAB, and the optimal operation problem of a VPP is studied for demonstrating the essential features of the proposed method.

The main contributions of this work are: (a) the carbon emission trading mechanism is introduced in the optimal dispatch problem of a VPP, whose low-carbon advantage is exploited; (b) economic and secure benefits brought by DR are addressed, through optimal dispatch of CSACSs and EVs.

This paper is organized as follows: the carbon emission trading mechanism and the dispatching framework of VPP are introduced in Section 2. The method used to address uncertainties of the generation outputs from renewable energy generation units is described in Section 3. The optimal dispatching problem of VPP and models of flexible loads are formulated in Section 4. Case studies and simulation results are presented in Section 5, and conclusions given in Section 6. 


\section{The Carbon Emission Trading Mechanism and Dispatching Framework}

\subsection{The Carbon Emission Trading Mechanism}

A carbon emission trading mechanism represents a market-oriented measure for achieving the goal of emission reduction. In 1997, three typical categories of carbon emission trading mechanism were proposed in the well-known Kyoto Protocol [27]: (1) Joint Implementation (JI); (2) Clean Development Mechanism (CDM); and (3) Emission Trading (ET). In CDM, the carbon emission credit of each participant is assured individually and the real-time carbon emission amount monitored. If the actual carbon emission amount in a specific time interval is lower than the credit, the participant could make profits by selling the surplus credit to the carbon trading market, and vice versa. In JI or ET, the total carbon emission amount is first determined, and then allocated to the participants. The permitted carbon emission amount could be traded among participants. However, it is difficult to appropriately determine the total carbon emission amount and the allocation method in JI/ET. Moreover, at present, CDM is mainly involved in China since it is deemed the most matching category with the developmental stage of domestic economy [28]. Thus, in this work CDM is assumed to be employed. In CDM, carbon emission credits, which can be regarded as the benchmark of carbon emissions, need to be pre-allocated to economic entities participating in the carbon trading.

In this work, each day is divided into 96 time periods with $15 \mathrm{~min}$ for each period/interval. It is assumed that the parameters remain unchanged in each time interval. Thus, the parameter values for a given time interval can be described by the ones at the beginning of the interval. The carbon emission credit $M_{D, t}$ for a VPP could be calculated by:

$$
M_{D, t}=\sum_{j=1}^{N} \varepsilon P_{j, t}
$$

where $N$ is the total number of generators in the VPP; $P_{j, t}$ is the generation output of generator $j$ at time $t ; \varepsilon$ is the carbon emission distribution coefficient per unit electrical energy of the VPP, which is determined by the "National Grid Baseline Emission Factor" issued by National Development and Reform Commission, China [28].

The carbon emission costs under carbon trading environment can be expressed as:

$$
\begin{gathered}
C_{t}^{c}=K_{C} \Delta M_{t} \\
\Delta M_{t}=M_{C, t}-M_{D, t} \\
M_{C, t}=\sum_{g=1}^{N_{G}} P_{g, t} Q_{g}
\end{gathered}
$$

where $C_{t}^{c}$ represents the carbon emission cost of the VPP at time $t ; K_{C}$ is the transaction price of the per unit carbon emission; $\Delta M_{t}$ is the part of the emission with $M_{C, t}$ as the actual carbon emission of the VPP at time $t$, and $M_{D, t}$ is the carbon emission credit at time $t$, while $\Delta M_{t}$ is the difference between them. If $M_{C, t}$ is lower than $M_{D, t}$, then the value of $\Delta M_{t}$ would be negative; $N_{G}$ is the number of gas turbines in the VPP; $P_{g, t}$ is the generation output of gas turbine $g$ at time $t ; Q_{g}$ is the per unit carbon emission intensity of the generation output of gas turbine $g$ [23]. Note that a negative value of $C_{t}^{c}$ means revenue from the carbon trading.

\subsection{The Dispatching Framework of the VPP}

An energy management system (EMS) is developed in each VPP to manage gas turbines, wind power units, photovoltaic units, EVs and other flexible loads. Appropriate price subsidies will be provided by the concerned agents in order to incentivize EV owners to register their EVs as schedulable devices. Accordingly, EV owners need to plug EVs into the power system concerned and 
to follow the charging/discharging scheduling in given time periods. EVs in the VPP are managed by a day-ahead submitting mechanism [29], in which EV owners submit the next-day usage information of EVs according to their preference, including the plug-in time, the plug-out time, the expected initial state of charge (SOC) and the target SOC when plugging out. The EMS receives the submitted information and determines the charging/discharging schedules of EVs of the next day.

The general dispatch framework of the VPP is depicted in Figure 1. Based on the predicted results of renewable energy generation outputs and load demands, day-ahead submitted information of EVs and the prices of electricity and carbon trading, the EMS of the VPP determines generation outputs of gas turbines at each time period of the next day, charging/discharging schedules of EVs, DR schedules and carbon emission trading outcomes. The electrical demands in the VPP can be satisfied by the DGs as well as the power supply from the connected distribution network. The VPP can gain economic profits by transmitting redundant power to the distribution network, and buy/sell carbon emission credits in the carbon trading market.

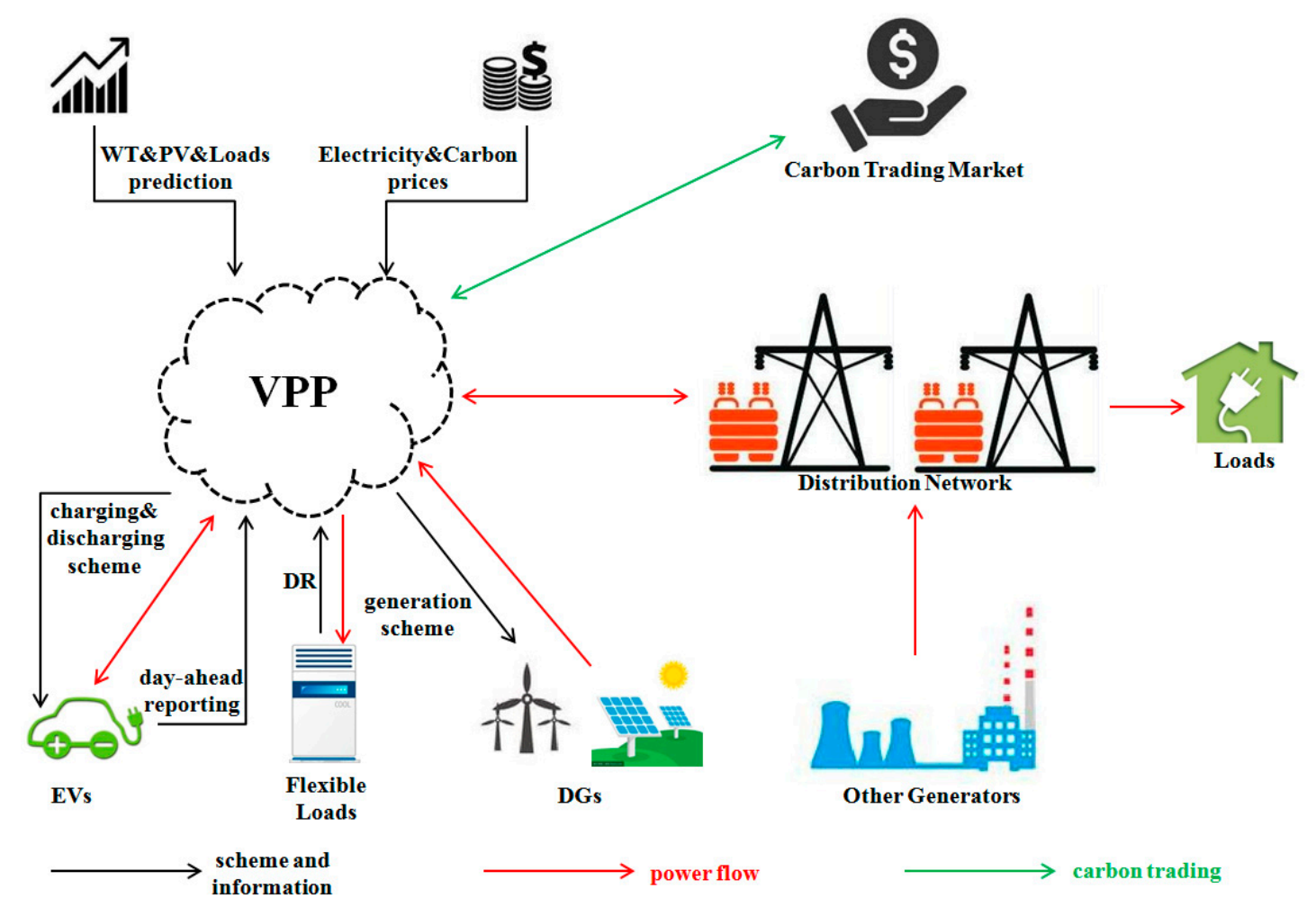

Figure 1. Illustration of the dispatching procedure in a VPP.

\section{Modeling of Uncertainties}

Intermittent renewable energy generation units in the VPP, such as wind power and photovoltaic units, result in uncertainties in VPP dispatching [30].

The generation output uncertainty of a wind generation unit is heavily related to the fluctuation of the wind speed. Based on the analysis of numerous statistical data, it is found that wind velocity follows the Weibull distribution [31] given by the following probability density function (PDF):

$$
f(v)=\frac{k}{c}\left(\frac{v}{c}\right)^{k-1} \exp \left[-\left(\frac{v}{c}\right)^{k}\right]
$$

where $v$ is the wind speed; $c$ is the scale parameter; $k$ is the shape parameter. 
The generation output of the wind turbine can be calculated by:

$$
P_{\text {wind }}=\left\{\begin{array}{l}
0 \quad v<v_{\text {in }} \quad \text { or } \quad v>v_{\text {out }} \\
P_{\text {rate }}^{\text {wind }} \frac{v^{3}-v_{\text {in }}^{3}}{v_{\text {rate }}^{3}-v_{\text {in }}^{3}} \quad v_{\text {in }} \leq v \leq v_{\text {rate }} \\
P_{\text {rate }}^{\text {wind }} v_{\text {rate }}<v \leq v_{\text {out }}
\end{array}\right.
$$

where $P_{\text {wind }}$ and $P_{\text {rate }}^{\text {wind }}$ are respectively the actual and rated outputs of the wind turbine; $v_{\text {in }}, v_{\text {rate }}$ and $v_{\text {out }}$ represent the cut-in, rated and cut-out wind speeds of the wind turbine, respectively.

Similarly, the solar irradiance follows the Beta distribution [31] given by the following PDF:

$$
f(r)=\frac{\Gamma(a+b)}{\Gamma(a) \Gamma(b)}\left(\frac{r}{r_{\max }}\right)^{a-1}\left(1-\frac{r}{r_{\max }}\right)^{b-1}
$$

where $\Gamma(\cdot)$ represents the Gamma function; $a$ and $b$ are both distribution shape parameters; $r$ and $r_{\max }$ are the actual and maximum solar irradiances, respectively.

The output of the photovoltaics $P_{P V}$ can be expressed as:

$$
P_{P V}=r A \eta_{P V}
$$

where $A$ is the area of the photovoltaic panel; $\eta_{P V}$ is the solar electric power conversion efficiency.

The outputs of the wind power and photovoltaics could be estimated within a range by the PDF equations shown in (5) and (7) at a specified confidence level [32]. It is assumed that the error between the estimated and actual outputs follows the normal distribution [33]. If the confidence level is $\alpha$, the relationship between the actual output and the range of the estimated value of a renewable energy generation unit can be described as:

$$
p_{R}\left(P_{k, t}^{-} \leq P_{k, t} \leq P_{k, t}^{+}\right) \geq \alpha
$$

where $p_{R}(\bullet)$ represents the probability function; $P_{k, t}$ is the actual output of renewable energy generation unit $k$ at time $t ; P_{k, t}^{-}$and $P_{k, t}^{+}$are respectively the minimum and maximum estimated values of $P_{k, t}$ at the confidence level $\alpha$. Equation (9) expresses that the probability of $P_{k, t}$ falling within the interval $\left[P_{k, t}^{-}, P_{k, t}^{+}\right]$is not less than $\alpha$.

If $P_{k, t}^{-}$is taken as the estimated value of $P_{k, t}$, the attained optimization result would be very conservative because it is practically impossible that all outputs of renewable energy generation units are less than their minimum estimated values. Thus, other methods should be considered to deal with the uncertainties.

The mean value and standard deviation of $P_{k, t}$ could be respectively expressed by:

$$
\begin{gathered}
\mu_{k, t}=\frac{1}{2}\left(P_{k, t}^{-}+P_{k, t}^{+}\right) \\
\sigma_{k, t}=\frac{P_{k, t}^{+}-P_{k, t}^{-}}{2 \phi^{-1}\left(\frac{1+\alpha}{2}\right)}
\end{gathered}
$$

where $\phi(\bullet)$ represents the cumulative distribution function of the standard normal distribution.

Let $\Omega_{q}$ be the set of all renewable energy generation units in the VPP. The total forecasted output of generation units in $\Omega_{q}$ could be approximately described by the normal distribution with the mean value and standard deviation respectively expressed as:

$$
\mu_{t}=\sum_{k \in \Omega_{q}} \mu_{k, t}
$$




$$
\sigma_{t}=\left(\sum_{k \in \Omega_{q}} \sigma_{k, t}^{2}\right)^{\frac{1}{2}}
$$

Equations (14) and (15) are introduced as the constraints of the generation outputs of renewable energy generating units:

$$
\begin{gathered}
\sum_{k \in \Omega_{q}} P_{k, t} \leq \mu_{t}+\sigma_{t} \phi^{-1}(1-\beta) \\
P_{k, t}^{-} \leq P_{k, t} \leq P_{k, t}^{+}
\end{gathered}
$$

where $\beta$ is the confidence level in the optimal dispatching of the VPP. In this way, the uncertainties are modeled with the aforementioned over-conservatism problem avoided.

\section{Problem Formulation}

In this section, the mathematical models of flexible loads and the VPP will be presented.

\subsection{Modeling of Flexible Loads}

DR is implemented by utilizing flexible loads, including CSACSs and EVs.

\subsubsection{Modeling of Temperature-controlled Devices}

\section{(1) Thermal Dynamic Equilibrium Equation in Buildings}

The heat absorbed by a building could be calculated by:

$$
C_{H}=B\left(\theta_{\text {out }}-\theta_{\text {in }}\right)+Q
$$

where $B$ is the heat transferring coefficient of the building; $\theta_{\text {out }}$ and $\theta_{\text {in }}$ respectively represent the outdoor and indoor temperatures; $Q$ is the instantaneous heat increments except for the heat transferred from the temperature difference, which is related to solar radiation, heat dissipation of household appliances, and others.

When the cold energy provided by refrigeration devices is equal to the heat absorbed by the building, the indoor temperature would basically be maintained. Accordingly, the thermal dynamic equilibrium equation in the building can be expressed as:

$$
C_{a} V \rho_{a} d \theta_{\text {in }}=\left(C_{H}-C_{D}\right) d t
$$

where $C_{a}$ is the specific heat capacity of the air; $V$ is the indoor capacity; $\rho_{a}$ represents the density of the air; $C_{D}$ is the cold energy provided by refrigeration devices.

By solving Equation (17), the continuous expression of the indoor temperature can be attained, and then be discretized as:

$$
\theta_{i n, t}=\theta_{i n, t-1} e^{-B \Delta t / C_{a} V \rho_{a}}+\left(1-e^{-B \Delta t / C_{a} V \rho_{a}}\right)\left(\frac{Q_{t}-C_{D, t}}{B}+\theta_{o u t, t}\right)
$$

\section{(2) Thermal Comfort}

Some temperature-controlled demands can be scheduled based on electricity market price signals without causing discomfort to the users, that is, the thermal comfort of consumers should be maintained within an acceptable range in dispatching the VPP.

The predicted mean vote (PMV) method [34] can be used to evaluate the thermal comfort level. The acceptable PMV range is between -0.5 and 0.5 [35]. Through appropriate simplification of the environmental factors, the relationship between PMV and temperature is formulated as [36]: 


$$
I_{P M V}= \begin{cases}0.3895 \times(\theta-26) & \theta \geq 26 \\ 0.4065 \times(-\theta+26) & \theta<26\end{cases}
$$

where $I_{P M V}$ is the PMV value in the building; $\theta$ represents the temperature.

According to Equation (19), the comfortable indoor temperature ranges between $24.8^{\circ} \mathrm{C}$ and $27.3^{\circ} \mathrm{C}$.

(3) Modeling of CSACS

A CSACS can be utilized to reduce the peak electricity demand of a given building. The modeling of a CSACS, including chillers, pumps, thermal storage tanks and other auxiliary equipment [37], is addressed here. The cold energy could be produced by chillers and stored/released by thermal storage tanks. Suppose that smart meters with the bi-direction communication capability are used in the building [38], then the CSACS can be dispatched with electricity price changes considered. The cold energy provided by a CSACS in each time interval can be expressed as:

$$
C_{D, i, t}=C_{p, i, t}-C_{s, i, t}+C_{r, i, t}
$$

where $C_{p, i, t}, C_{s, i, t}$ and $C_{r, i, t}$ represent the produced, stored and released cold energy of CSACS $i$ at time $t$, respectively.

The following operation constraint of each CSACS should be respected:

$$
\begin{gathered}
0 \leq I_{s, i, t}+I_{r, i, t} \leq 1 \\
0 \leq C_{p, i, t} \leq C_{p}^{\max } \\
0 \leq C_{s, i, t} \leq I_{s, i, t} C_{s}^{\max } \\
0 \leq C_{r, i, t} \leq I_{r, i, t} C_{r}^{\max } \\
0 \leq S_{i, t}^{c} \leq S^{c, \max } \\
S_{i, t}^{c}=S_{i, t-1}^{c}+\left(C_{s, i, t} \eta_{s}-C_{r, i, t} / \eta_{r}\right) \Delta t
\end{gathered}
$$

where $I_{s, i, t}$ and $I_{r, i, t}$ are respectively the binary decision variables used to represent the storing and releasing status of CSACS $i$ at time $t ; C_{p}^{\max }, C_{s}^{\max }$ and $C_{r}^{\max }$ are respectively the maximum produced, stored and released cold energy in each time interval; $S_{i, t}^{c}$ is the cold energy stored in CSACS $i$ at time $t ; S^{c, \max }$ is the capacity of the storage tank; $\eta_{s}$ and $\eta_{r}$ represent the storing and releasing efficiencies, respectively.

Equations (21)-(24) represent the constraints associated with the production, storage and release of cold energy. The capacity limitation of the storage tank is demonstrated by Equation (25). Equation (26) represents the cold energy conservation of the CSACS.

The power consumed by a CSACS at time $t$ can be calculated by:

$$
P_{i, t}=\frac{C_{p, i, t}}{\mu_{p}}+\mu_{s} C_{s, i, t}+\mu_{r} C_{r, i, t}
$$

where $\mu_{p}$ is the energy efficiency ratio [39] for describing the relationship between the cooling effect and the electricity consumption of the chiller; $\mu_{s}$ and $\mu_{r}$ are the electric power conversion coefficients of storing and releasing cold energy, respectively.

\subsubsection{Modeling of EVs}

EVs could act as flexible loads in a smart grid environment. The charging and discharging of EVs can be scheduled with a certain degree of flexibility. Moreover, the energy stored in the batteries of 
EVs can be transmitted back to the power network concerned, i.e., the so-called vehicle-to-grid (V2G) function. The following operation constraints of EVs should be respected:

$$
\begin{gathered}
p_{v, t}^{c}=u_{v, t}^{c} p_{v}^{c} \\
p_{v, t}^{d}=u_{v, t}^{d} p_{v}^{d} \\
u_{v, t}^{c}+u_{v, t}^{d} \leq u_{v, t}^{i n} \\
S_{v, \min } \leq S_{v, t} \leq S_{v, \max } \\
S_{v, t_{v}^{a}}=S_{v, a} \\
S_{v, d} \leq S_{v, t_{v}^{d}} \leq S_{v, \max } \\
S_{v, t}=S_{v, t-1}+\frac{u_{v, t}^{c} p_{v, t}^{c} \eta_{v}^{c}}{E^{\max }} \Delta t-\frac{u_{v, t}^{d} t_{v, t}^{d}}{E^{\max } \eta_{v}^{d}} \Delta t
\end{gathered}
$$

where $u_{v, t}^{c}$ and $u_{v, t}^{d}$ are the binary decision variables respectively used to represent the charging and discharging status of EV $v$ at time $t ; p_{v}^{c}$ and $p_{v}^{d}$ respectively represent the rated charging and discharging power of EV $v$; binary decision variable $u_{v, t}^{\text {in }}$ represents the dispatching status of EV $v$ at time $t ; S_{v, t}$ is SOC of EV $v$ at time $t ; S_{v, \min }$ and $S_{v, \max }$ respectively represent the minimum and maximum SOCs of $\mathrm{EV} v ; t_{v}^{a}$ and $t_{v}^{d}$ are respectively the arrival time and the departure time of EV $v ; S_{v, a}$ is the SOC of EV $v$ at the arrival time; $S_{v, d}$ is the target SOC of EV $v$ at the departure time; $\eta_{v}^{c}$ and $\eta_{v}^{d}$ are respectively the charging and discharging efficiencies of $\mathrm{EV} v ; E^{\mathrm{max}}$ is the battery capacity.

Equations (28)-(30) represent the constraints of the charging and discharging behaviors of EVs. The constraints of SOC are represented by Equations (31)-(33). The change of SOC of EVs over two continuous periods is described by Equation (34).

\subsection{Objective Function}

The optimal dispatching problem is formulated with an objective of maximizing the profit. The objective function includes two parts, i.e., the revenues from the electricity trading and the costs associated with the power generation, carbon trading as well as the charging/discharging of EVs, and can be formulated as:

$$
\max \sum_{t=1}^{T}\left[\lambda_{t}^{s} P_{t}^{s}-\left(C_{t}^{g a s}+C_{t}^{c}+C_{t}^{E V}\right)\right]
$$

where $T$ represents the number of time intervals in a day; $\lambda_{t}^{s}$ is the electricity market price at time $t ; P_{t}^{s}$ is the power exchanged between the VPP and the distribution network at time $t$, and takes a negative value when the VPP purchases electricity from the distribution network; $C_{t}^{g a s}, C_{t}^{c}$ and $C_{t}^{E V}$ represent the costs of the gas turbines, carbon trading and charging/discharging of EVs at time $t$, respectively.

The costs of gas turbines include the operation costs, modeled as a piecewise linear function [6], and the start-up/shut-down costs:

$$
\begin{gathered}
C_{t}^{g a s}=\sum_{g=1}^{N_{G}}\left[k_{g, 0} u_{g, t}+\left(\sum_{j=1}^{n_{j}} k_{g, j} P_{g, j, t}\right)+C_{g, t}^{S U}+C_{g, t}^{S D}\right] \\
P_{g, t}=\sum_{j=1}^{n_{j}} P_{g, j, t} \\
C_{g, t}^{S U}=\max \left\{\lambda_{g}^{S U}\left(u_{g, t}-u_{g,(t-1)}\right), 0\right\} \\
C_{g, t}^{S D}=\max \left\{\lambda_{g}^{S D}\left(u_{g,(t-1)}-u_{g, t}\right), 0\right\}
\end{gathered}
$$


where $k_{g, 0}$ is the fixed operation cost of gas turbine $g$; binary decision variable $u_{g, t}$ is the on/off status of gas turbine $g$ at time $t ; n_{j}$ is the number of the pieces of the linearized operation cost function; $k_{g, j}$ is the slope of the $j$-th piece; $P_{g, j, t}$ is the power output from the $j$-th piece of gas turbine $g$ at time $t ; C_{g, t}^{S U}$ and $C_{g, t}^{S D}$ respectively represent the start-up and shut-down costs of gas turbine $g$ at time $t$, while $\lambda_{g}^{S U}$ and $\lambda_{g}^{S D}$ are the corresponding costs for a single time. If gas turbine $g$ starts up at time $t, C_{g, t}^{S U}$ and $C_{g, t}^{S D}$ are $\lambda_{g}^{S U}$ and 0 , respectively. If gas turbine $g$ shuts down at time $t, C_{g, t}^{S U}$ and $C_{g, t}^{S D}$ are 0 and $\lambda_{g}^{S D}$, respectively. Otherwise, $C_{g, t}^{S U}$ and $C_{g, t}^{S D}$ are all equal to 0 .

The carbon trading cost at time $t$ can be calculated by Equation (2).

The charging/discharging costs of EVs at time $t$ can be expressed as:

$$
C_{t}^{E V}=\sum_{v=1}^{N_{v}}\left(\lambda_{t}^{d} p_{v, t}^{d}-\lambda_{t}^{c} p_{v, t}^{c}\right)
$$

where $N_{v}$ is the number of EVs; $p_{v, t}^{c}$ and $p_{v, t}^{d}$ respectively represent the charging and discharging power of EV $v$ at time $t$, while $\lambda_{t}^{c}$ and $\lambda_{t}^{d}$ are the corresponding prices at time $t$.

\subsection{Other Constraints}

\subsubsection{Constraints of Gas Turbines}

(1) Power output constraints:

$$
u_{g, t} P_{g}^{\min } \leq P_{g, t} \leq u_{g, t} P_{g}^{\max }
$$

where $P_{g}^{\min }$ and $P_{g}^{\max }$ are the minimum and maximum power outputs of gas turbine $g$.

(2) Ramping constraints:

$$
-R_{g}^{D} \Delta t \leq P_{g, t}-P_{g,(t-1)} \leq R_{g}^{U} \Delta t
$$

where $R_{g}^{U}$ and $R_{g}^{D}$ are the ramping-up and ramping-down limits of gas turbine $g$.

\subsubsection{Power Balance Constraint:}

$$
\sum_{g=1}^{N_{G}} P_{g, t}+\sum_{k=1}^{N_{q}} P_{k, t}+\sum_{v=1}^{N_{v}} p_{v, t}^{d}=P_{t}^{s}+\sum_{v=1}^{N_{v}} p_{v, t}^{c}+\sum_{i=1}^{N_{c}} P_{i, t}+P_{t}^{R}
$$

where $N_{q}$ is the total number of renewable energy generating units; $N_{c}$ is the number of CSACSs; $P_{t}^{R}$ is the fixed/inflexible electrical demand at time $t$ in the VPP.

\subsection{Solving Method}

The developed optimal dispatching model for a VPP includes Equations (18)-(43). The objective function and all constraints are linear, but include some binary decision variables. Therefore, the optimal dispatching model is a mixed integer linear planning (MILP) problem. The well-developed commercial solver CPLEX in the YALMIP/MATLAB toolbox is employed to solve the MILP problem.

\section{Case Studies}

\subsection{Parameter Setting}

A VPP, with two gas turbines, one wind power unit, one photovoltaic unit and 50 intelligent energy consumers included, is employed to demonstrate the developed method. Each intelligent energy consumer is equipped with a CSACS and an EV, with both acting as dispatchable DR. The parameter settings of the gas turbines are shown in Table A1 in the Appendix A. The actual power outputs of the wind power unit and photovoltaic unit in a typical day, which are unknown in making the 
dispatching strategy and attained by sampling from probabilistic models, are shown in Figure A1. The confidence levels, $\alpha$ and $\beta$, are both assumed to be 95\% [33]. The model presented in Section 3 is employed to address the uncertainties of the forecast intervals and then included in the optimal dispatch model. The initial SOCs of the EVs are random numbers uniformly distributed between 0.15 and 0.35 . The departure and arrival time points of the EVs respectively follow the probability density distributions described by (44) and (45) [29]:

$$
\begin{aligned}
& f_{d}(x)= \begin{cases}\frac{1}{\sqrt{2 \pi} \sigma_{d}} \exp \left(-\frac{\left(x-\mu_{d}\right)^{2}}{2 \sigma_{d}^{2}}\right) & 0<x \leq \mu_{d}+12 \\
\frac{1}{\sqrt{2 \pi} \sigma_{d}} \exp \left(-\frac{\left(x-24-\mu_{d}\right)^{2}}{2 \sigma_{d}{ }^{2}}\right) & \mu_{d}+12<x \leq 24\end{cases} \\
& f_{a}(x)= \begin{cases}\frac{1}{\sqrt{2 \pi} \sigma_{a}} \exp \left(-\frac{\left(x+24-\mu_{a}\right)^{2}}{2 \sigma_{a}^{2}}\right) & 0<x \leq \mu_{a}-12 \\
\frac{1}{\sqrt{2 \pi} \sigma_{a}} \exp \left(-\frac{\left(x-\mu_{a}\right)^{2}}{2 \sigma_{a}^{2}}\right) & \mu_{a}-12<x \leq 24\end{cases}
\end{aligned}
$$

where $\mu_{d}=8.92, \sigma_{d}=3.24, \mu_{a}=17.47, \sigma_{a}=3.41$.

Other parameters of the EVs are described in Table A2 [40]. The charging and discharging prices are shown in Figure A2. The parameters of the CSACS are described in Table A3. The instantaneous heat increment of each intelligent energy consumer and the outdoor temperature in a typical summer day are shown in Figure A3 [41]. In the case study, it is assumed that all consumers are of similar thermal characteristics. Daily fixed/inflexible electrical demands of all intelligent energy consumers are shown in Figure 2. The time-of-use (TOU) electricity prices are shown in Table 1 [40]. The carbon emission price $K_{C}$ is assumed to be $0.25 \$ \cdot \mathrm{kg}^{-1}$.

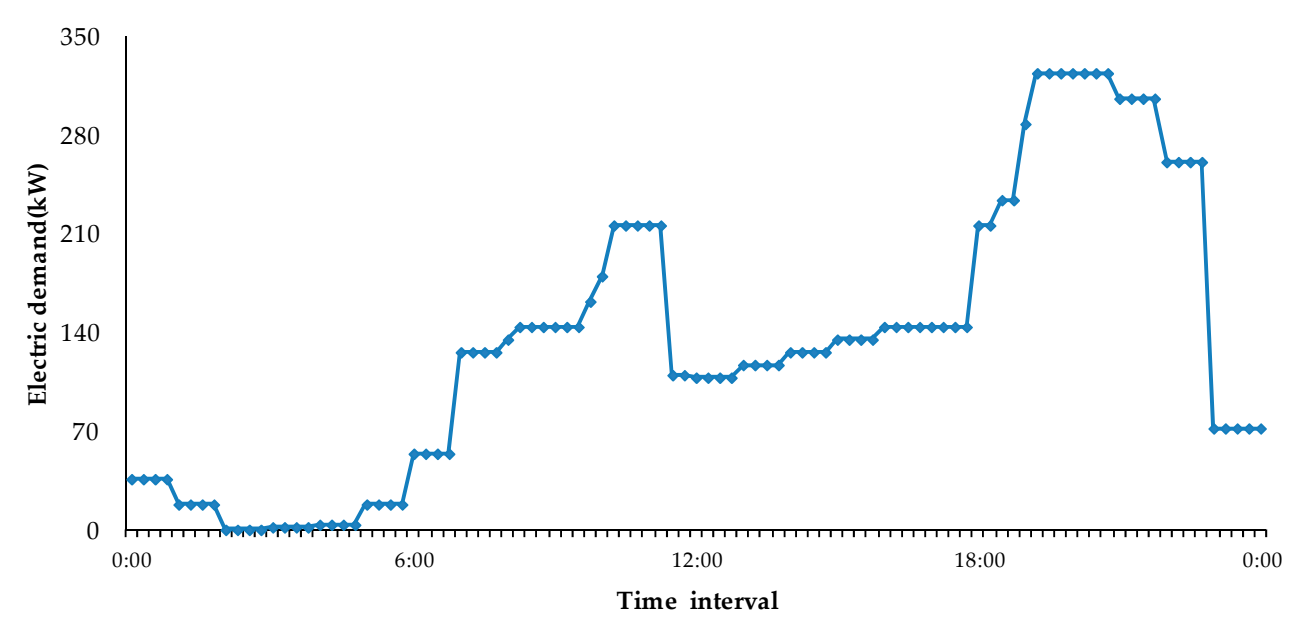

Figure 2. Daily total fixed/inflexible electrical demands of 50 intelligent energy consumers.

Table 1. Time-of-use (TOU) electricity prices.

\begin{tabular}{cccccc}
\hline Time Period & TOU & Price $\mathbf{( \$ / k W h )}$ & Time Period & TOU & Price (\$/kWh) \\
\hline 7:00-8:15 & Mid-peak & 0.103 & $18: 00-18: 45$ & Sub-peak & 0.164 \\
8:30-10:15 & Sub-peak & 0.164 & $19: 00-20: 45$ & On-peak & 0.174 \\
10:30-11:30 & On-peak & 0.174 & $21: 00-22: 45$ & Sub-peak & 0.164 \\
11:45-17:45 & Mid-peak & 0.103 & $23: 00-6: 45$ & Off-peak & 0.041 \\
\hline
\end{tabular}

\subsection{Simulation Results}

The dispatching results with and without DR are compared in Figure 3. It is found that flexible loads automatically respond to the change of electricity prices and act in a way that mitigates the 
peak-valley difference, which has a positive influence on the operation of the VPP. In addition, the profit of the VPP increases from $\$ 1967.74$ to $\$ 2221.97$ with the utilization of DR resources. Thus, the economic effectiveness brought by DR is demonstrated. The performances of CSACSs, EVs and carbon trading will be described in detail in the next three subsections.

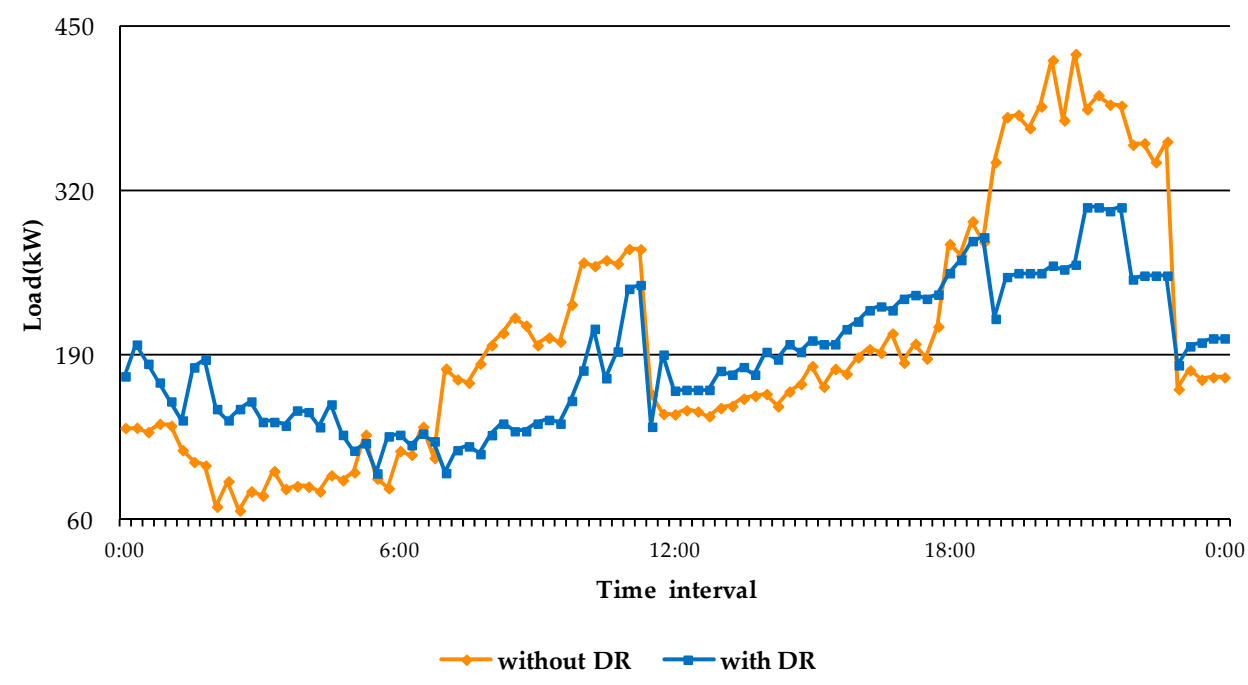

Figure 3. Comparisons between the loads in the VPP for situations with and without DR.

\subsubsection{Performance of CSACSs}

As described before, the cold energy of CSACSs could be provided by the electric-consuming chillers and/or the thermal storage tank. The electric power and the cold energy storage curves of a typical CSACS are depicted in Figure 4.

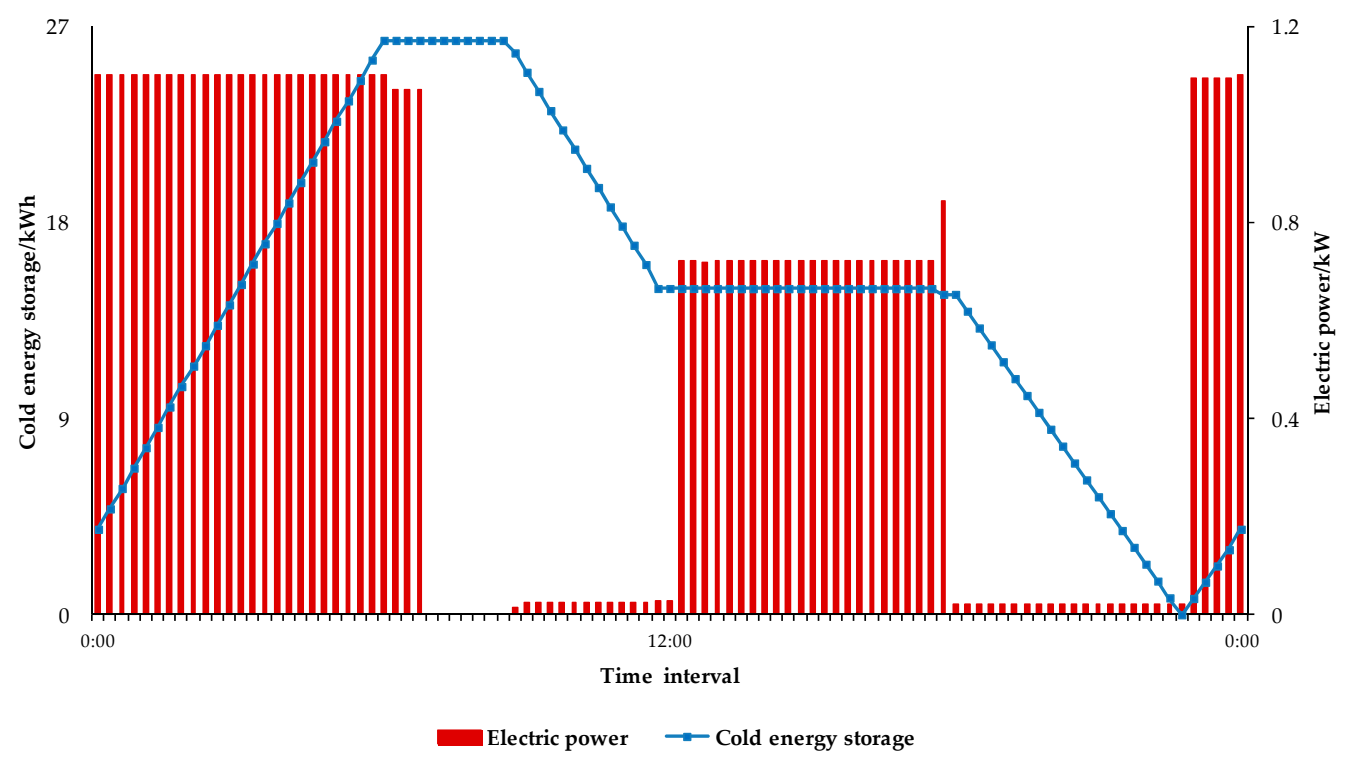

Figure 4. Electrical power demand and cold energy storage of a typical CSACS.

As shown in the curves, the cold energy is produced and simultaneously stored in 23:00-6:45, during which the electricity prices are the lowest. During 11:45-17:30, the cooling demand is satisfied by chillers instead of the stored ones, for that the utilization of the stored energy in the upcoming peak-price periods will bring more economic benefits. The thermal storage tank releases cold energy in peak-price periods to maintain the thermal comfort level of the consumers, and thus to reduce the cost 
of electricity consumption by the chillers. Meanwhile, it can be found that the power of the CSACSs is concentrated in the valley-load hours as known from the fixed/inflexible demand curve. Therefore, the CSACSs also make a great contribution to the improvement of the load curve profile.

\subsubsection{Performance of EVs}

The charging/discharging power of EVs and the SOC variation of a typical EV in the dispatching procedure are depicted in Figures 5 and 6, respectively.

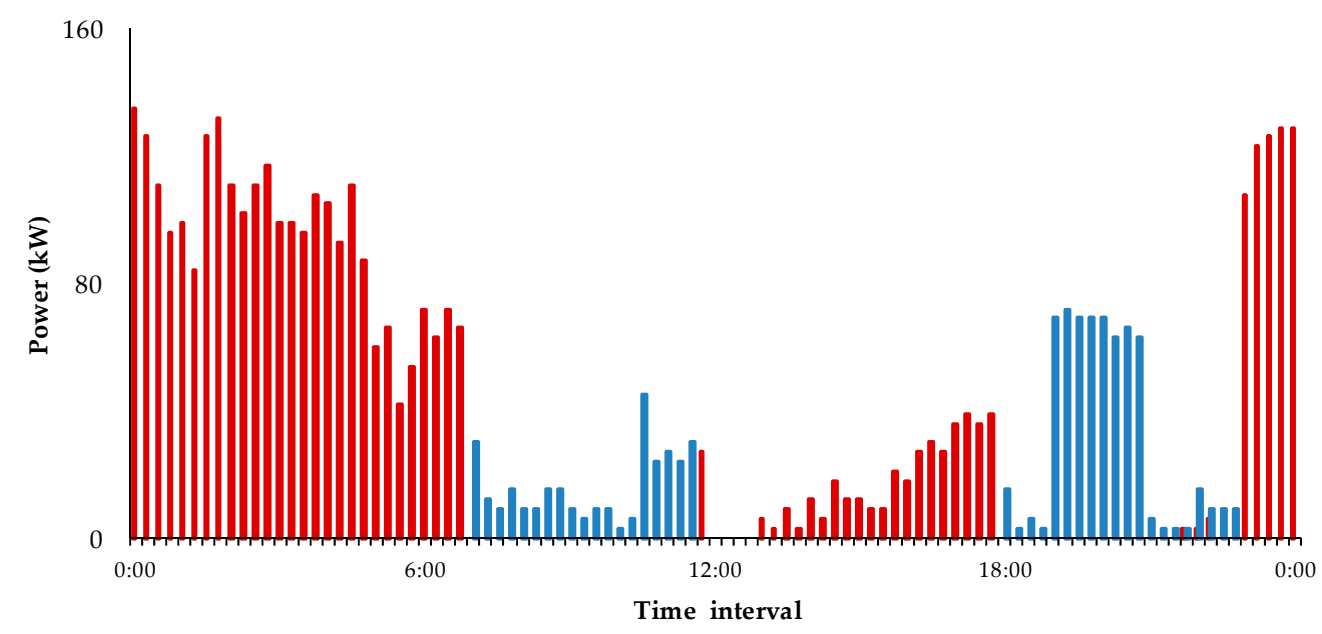

$\square$ EV charging power EV discharging power

Figure 5. Daily charging and discharging power curves of EVs on a typical day.

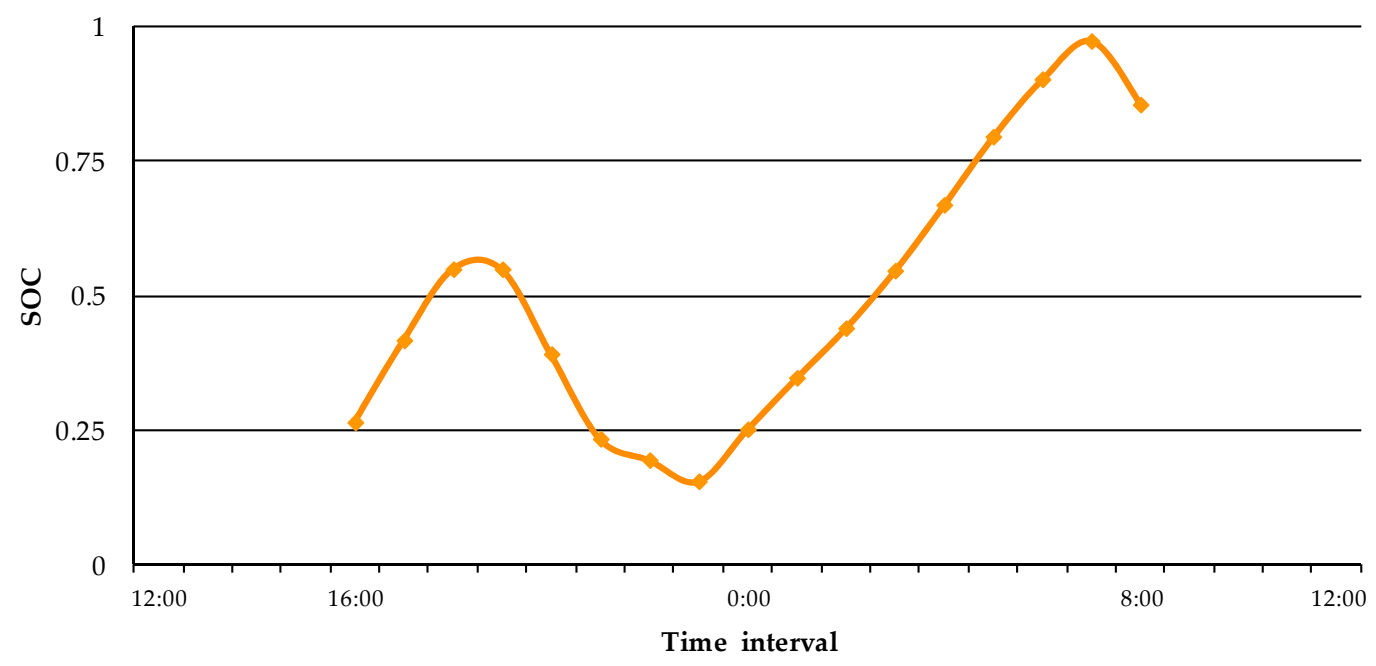

Figure 6. Daily SOC curve of a typical EV.

It is shown that EVs discharge on a large scale in 8:30-11:30 and 18:00-22:45, which are both peak-price periods. In these two periods, EVs discharge to satisfy the demands, thus the VPP has more redundant power sold to the distribution network. The charging power of EVs is concentrated in 23:00-6:45 and 11:45-17:45, during which the electricity prices are lower, i.e., $\$ 0.041$ and $\$ 0.103$, respectively. Similarly, the EV charging is typically concentrated in low electricity price periods and discharging in high electricity price periods, as shown in Figure 6. Therefore, the significant economic performances of EVs are demonstrated with respect to both a group of EVs and a single EV. It is also 
worth mentioning that centralized discharging of EVs is also carried out in the peak-load periods, and vice versa. Thus, the EVs also play an important role in load-shifting.

Moreover, excessive electricity is produced by the wind power unit in 23:00-6:45, during which the CSACSs and EVs consume large amount of power. Thus, both CSACSs and EVs are beneficial for accommodating wind power generation.

\subsubsection{Environmental Benefits of the VPP}

The amount of carbon emission reduced from $4.68 \mathrm{t}$ to $3.57 \mathrm{t}$ due to the introduction of the carbon emission trading. Given the electricity market environment, the generation outputs of the gas turbines are heavily dependent on the carbon trading price $K_{C}$.

Therefore, it is necessary to investigate the sensitivity of the generation outputs of the gas turbines with respect to $K_{C}$, with other parameters fixed. Figure 7 illustrates the generation output curves of these two gas turbines under three different carbon emission prices. Compared with gas turbine 1 , gas turbine 2 has lower carbon emission intensity but higher operation cost.

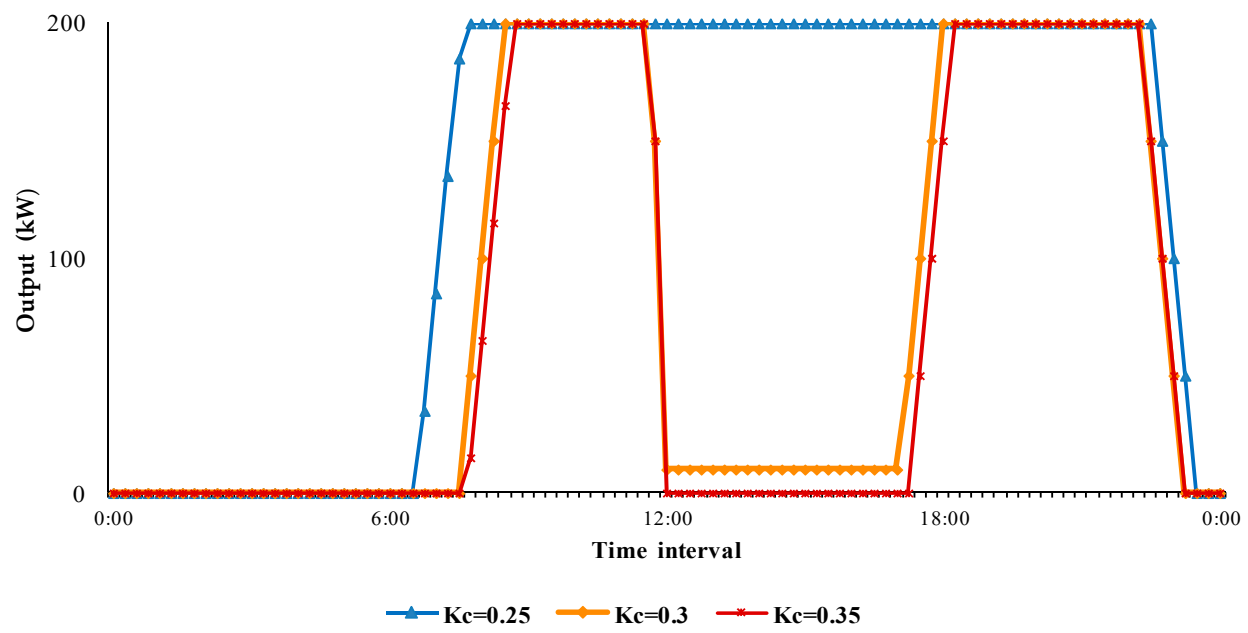

(a)

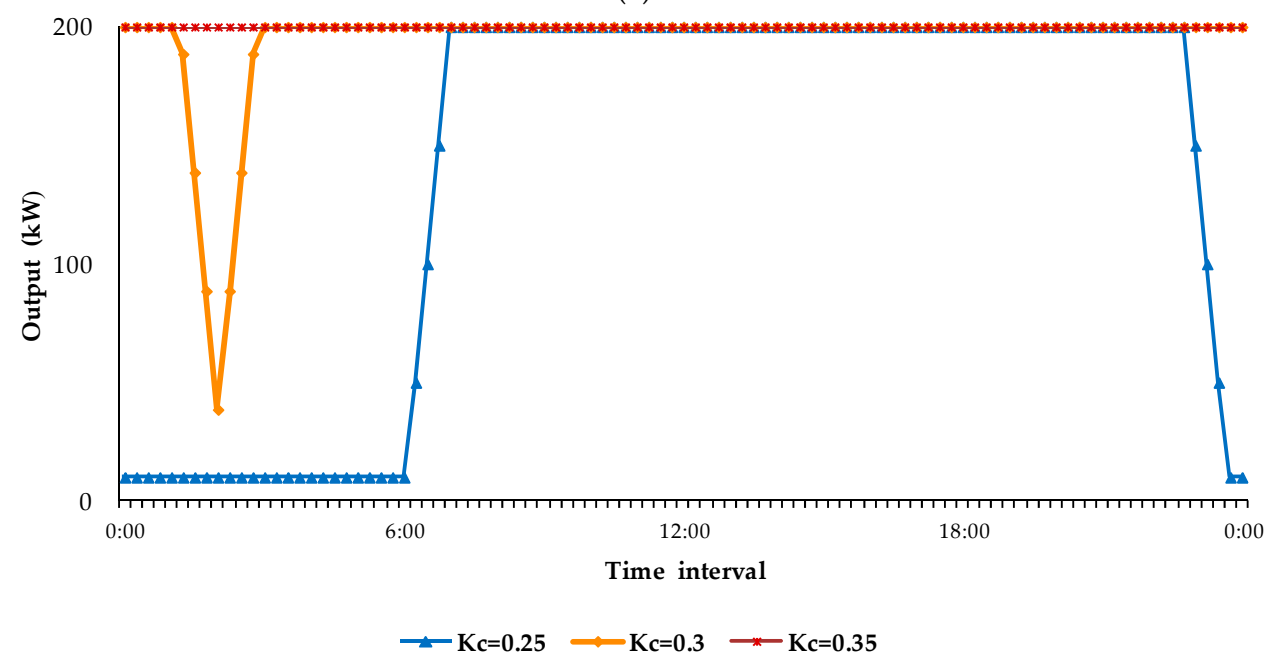

(b)

Figure 7. Daily generation output curves of two gas turbines under three different carbon prices.

(a) Gas turbine 1; (b) Gas turbine 2. 
It is shown that the power output of the low-carbon generator (gas turbine 2) increases with the rises of $K_{C}$ while the power output of gas turbine 1 decreases at the same time. As a result, the VPP could gain more benefit from the carbon trading. Carbon emission amounts and VPP profits under different values of $K_{C}$ are shown in Table 2 . When $K_{C}$ rises from $0.25 \$ \cdot \mathrm{kg}^{-1}$ to $0.3 \$ \cdot \mathrm{kg}^{-1}$, by increasing the generation output of low-carbon generator (gas turbine 2) as well as limiting the generation output of gas turbine 1, the carbon emission amount is reduced and more profits attained at the same time. When $K_{C}$ rises from $0.3 \$ \cdot \mathrm{kg}^{-1}$ to $0.35 \$ \cdot \mathrm{kg}^{-1}$, the reduction of carbon emission amount is no longer evident, because the generation output of gas turbine 2 has almost reached its maximum level at all time intervals, as shown in Figure 7. The amount of carbon emission will ultimately decrease to a fixed value with the increasing of the carbon price.

Table 2. Carbon emission amount and VPP profits under three different carbon prices.

\begin{tabular}{ccc}
\hline Carbon Price (\$/kg) & Carbon Emission Amount (t) & VPP Profit (\$) \\
\hline 0.25 & 3.5708 & 221.0914 \\
0.3 & 3.0989 & 406.8923 \\
0.35 & 3.0490 & 492.1817 \\
\hline
\end{tabular}

In order to illustrate the environmental benefits of EVs, two scenarios are analyzed: (1) $50 \mathrm{EV}$ cars in the VPP; (2) 50 fuel-consuming cars in the VPP with $\mathrm{CO}_{2}$ emission $181 \mathrm{~g} / \mathrm{km}$ for each car [42]. Simulation results show that the daily carbon emission amount of the VPP in Scenario 1 is less than that in Scenario 2 by $1.08 \mathrm{t}$. Therefore, it is expected that wide employment of EVs, as substitutions of conventional fossil fuel cars, could greatly contribute to environmental benefits as manifested by carbon emission reduction.

\section{Conclusions}

In this paper, an optimal dispatching model of a VPP with gas turbines, wind power, photovoltaics and flexible loads including CSACSs and EVs aggregated, is established. Uncertainties in generation outputs of renewable energy generating units are modeled by probability distributions. DR is implemented by coordinated utilization of flexible loads. Participation in carbon trading mechanism for the VPP is considered to explore its eco-friendly characteristics. Based on the proposed methodological architecture, a MILP optimization model with the objective of maximizing the VPP profit is developed, and solved by YALMIP/CPLEX. The performance of the developed method is demonstrated through case studies. The following conclusions are attained:

(a) If thermal storage is available, the power consumption of CSACSs should be scheduled to off-peak price periods while the thermal comfort requirement of users should be taken into account.

(b) EVs exhibit good performance in cost-saving, load-shifting as well as carbon-reduction. The redundant wind power can be well accommodated by CSACSs and EVs.

(c) A higher carbon emission price could promote the employment of low-carbon generation units in the VPP.

(d) With the ever-worsen environment, low-carbon generation units should be more widely employed.

(e) Flexible loads should be explored to the greatest extent so as to promote the economics and security of the VPP concerned.

A VPP could gain more benefits by appropriately participating in various kinds of markets, but only the CDM is considered in this paper, and further extension of the research work is demanding. The participation strategy of a VPP in various time-scale electricity markets, different kinds of ancillary service markets and emission trading markets is an important issue to be addressed in our future research efforts. 
Author Contributions: Z.L. proposed the methodological framework and mathematical model, and performed the simulations; W.Z., F.Q., L.W. and B.Z. designed the algorithm, reviewed and polished the manuscript; F.W. organized the research team, reviewed and improved the methodological framework and implementation algorithm; Y.X. analyzed the results, reviewed the manuscript and provided suggestions. All authors discussed the simulation results and agreed for submission.

Acknowledgments: This work is jointly supported by National Natural Science Foundation of China (No. 51477151), and a Science and Technology Project of State Grid Corporation of China (No. 5211JY180006).

Conflicts of Interest: The authors declare no conflict of interest.

\section{Nomenclature}

\begin{tabular}{|c|c|}
\hline DR & Demand response \\
\hline VPP & Virtual power plant \\
\hline DSM & Demand side management \\
\hline CSACS & Chilled water thermal storage air conditioning systems \\
\hline EV & Electric vehicle \\
\hline MILP & Mixed integer linear programming \\
\hline CDM & Clean development mechanism \\
\hline EMS & Energy management system \\
\hline PMV & Predicted mean vote \\
\hline SOC & State of charge \\
\hline PDF & Probability density function \\
\hline$M_{C, t}$ & Actual carbon emission of the VPP at time $t(\mathrm{~kg})$ \\
\hline$M_{D, t}$ & Carbon emission credit of the VPP at time $t(\mathrm{~kg})$ \\
\hline$K_{C}$ & Transaction price of the per unit carbon emission $\left(\$ \cdot \mathrm{kg}^{-1}\right)$ \\
\hline$Q_{g}$ & Per unit carbon emission intensity of gas turbine $g(\mathrm{~kg} / \mathrm{kW})$ \\
\hline$\varepsilon$ & Carbon emission distribution coefficient per unit electrical energy $(\mathrm{kg} / \mathrm{kWh})$ \\
\hline$P_{\text {wind }}$ & Output of the wind turbine $(\mathrm{kW})$ \\
\hline$P_{\text {rate }}^{\text {wind }}$ & Rated output of the wind turbine (kW) \\
\hline$v_{\text {in }}, v_{\text {rate }}, v_{\text {out }}$ & Cut-in, rated, and cut-out wind speeds of the wind turbine \\
\hline$P_{P V}$ & Output of the photovaltaics $(\mathrm{kW})$ \\
\hline$r$ & Solar irradiance $\left(\mathrm{kW} / \mathrm{m}^{2}\right)$ \\
\hline$A$ & Area of the photovoltaic panel $\left(\mathrm{m}^{2}\right)$ \\
\hline$P_{k, t}$ & Actual output of renewable energy generation unit $k$ at time $t(\mathrm{~kW})$ \\
\hline$P_{k, t}^{+}$ & Maximum estimated value of $P_{k, t}(\mathrm{~kW})$ \\
\hline$P_{k, t}^{-}$ & Minimum estimated value of $P_{k, t}(\mathrm{~kW})$ \\
\hline$\theta_{\text {in,t }}$ & Indoor temperature at time $t\left({ }^{\circ} \mathrm{C}\right)$ \\
\hline$\theta_{\text {out }, t}$ & Outdoor temperature at time $t\left({ }^{\circ} \mathrm{C}\right)$ \\
\hline$B$ & Heat transferring coefficient of the building \\
\hline$Q_{t}$ & Instantaneous heat energy increments at time $t(\mathrm{kWh})$ \\
\hline$C_{a}$ & Specific heat capacity of the air $\left(\mathrm{J} /\left(\mathrm{kg} \cdot{ }^{\circ} \mathrm{C}\right)\right)$ \\
\hline$\rho_{a}$ & Density of the air $\left(\mathrm{kg} / \mathrm{m}^{3}\right)$ \\
\hline$V$ & Indoor capacity of the building $\left(\mathrm{m}^{3}\right)$ \\
\hline$I_{P M V}$ & PMV value in the building \\
\hline$I_{s, i, t}$ & Binary decision variable of the storing status of CSACS $i$ at time $t$ \\
\hline$I_{r, i, t}$ & Binary decision variable of the releasing status of CSACS $i$ at time $t$ \\
\hline$C_{D, i, t}$ & Total provided cold energy of CSACS $i$ at time $t(\mathrm{kWh})$ \\
\hline$C_{p, i, t}$ & Produced cold energy of CSACS $i$ at time $t(\mathrm{kWh})$ \\
\hline$C_{s, i, t}$ & Stored cold energy of CSACS $i$ at time $t(\mathrm{kWh})$ \\
\hline$C_{r, i, t}$ & Released cold energy of CSACS $i$ at time $t(\mathrm{kWh})$ \\
\hline$P_{i, t}$ & Power consumed by CSACS $i$ at time $t(\mathrm{~kW})$ \\
\hline$S_{i, t}^{c}$ & Cold energy stored in CSACS $i$ at time $t(\mathrm{kWh})$ \\
\hline$\eta_{r}, \eta_{s}$ & Releasing and storing efficiencies of the CSACS \\
\hline$\mu_{p}$ & Energy efficiency ratio of the CSACS \\
\hline$\mu_{r}, \mu_{s}$ & Electric power conversion coefficients of releasing and storing cold energy \\
\hline
\end{tabular}


$u_{v, t}^{c} \quad$ Binary decision variable of charging status of EV $v$ at time $t$

$u_{v, t}^{d} \quad$ Binary decision variable of discharging status of EV $v$ at time $t$

$u_{v, t}^{i n} \quad$ Binary decision variable of dispatching status of EV $v$ at time $t$

$p_{v, t}^{c} \quad$ Charging power of EV $v$ at time $t(\mathrm{~kW})$

$p_{v, t}^{d} \quad$ Discharging power of EV $v$ at time $t(\mathrm{~kW})$

$S_{v, t} \quad$ SOC of EV $v$ at time $t$

$S_{v, a} \quad$ SOC of EV $v$ at the arrival time

$S_{v, d} \quad$ Target SOC of EV $v$ at the departure time

$E^{\max } \quad$ Battery capacity of each EV $(\mathrm{kWh})$

$\eta_{v}^{c} \quad$ Charging efficiency of EV $v$

$\eta_{v}^{d} \quad$ Discharging efficiency of EV $v$

$u_{g, t} \quad$ On/off status of gas turbine $g$ at time $t$

$P_{t}^{s} \quad$ Power exchanged between VPP and the distribution network at time $t(\mathrm{~kW})$

$P_{g, t} \quad$ Output of gas turbine $g$ at time $t(\mathrm{~kW})$

$R_{g}^{U} \quad$ Ramping-up limit of gas turbine $g(\mathrm{~kW})$

$R_{g}^{D} \quad$ Ramping-down limit of gas turbine $g(\mathrm{~kW})$

$\lambda_{t}^{s} \quad$ Electricity market price at time $t(\$ / \mathrm{kWh})$

$C_{t}^{\text {gas }} \quad$ Costs of gas turbines at time $t(\$)$

$C_{g, t}^{S U} \quad$ Start-up costs of gas turbine $g$ at time $t(\$)$

$C_{g, t}^{S D} \quad$ Shut-down costs of gas turbine $g$ at time $t(\$)$

$C_{t}^{C} \quad$ Costs of carbon trading at time $t(\$)$

$C_{t}^{E V} \quad$ Costs of charging/discharging of EVs at time $t(\$)$

$N_{G} \quad$ Number of gas turbines

$N_{q} \quad$ Number of renewable energy generating units

$\mathrm{Nv} \quad$ Number of EVs

$N_{c} \quad$ Number of CSACSs

\section{Appendix A}

Table A1. Parameters of gas turbines.

\begin{tabular}{ccccccc}
\hline Gas Turbine & $\begin{array}{c}\text { (Maximum/Minimum } \\
\text { Output)/kW }\end{array}$ & $\begin{array}{c}\text { (Ramping-Up/Down } \\
\text { Limits)/(kW/h) }\end{array}$ & $\begin{array}{c}\text { Slope of Piece } \\
\text { I (\$/kW) }\end{array}$ & $\begin{array}{c}\text { Slope of Piece } \\
\text { II (\$/kW) }\end{array}$ & $\begin{array}{c}\text { Slope of Piece } \\
\text { III (\$/kW) }\end{array}$ & $\begin{array}{c}\text { Carbon Emission } \\
\text { Intensity [g·(kWh) }\end{array}$ \\
\hline 1 & $200 / 10$ & $200 / 200$ & 0.026 & 0.031 & 0.036 \\
2 & $200 / 10$ & $200 / 200$ & 0.076 & 0.081 & 0.086 & 736.0 \\
\hline
\end{tabular}

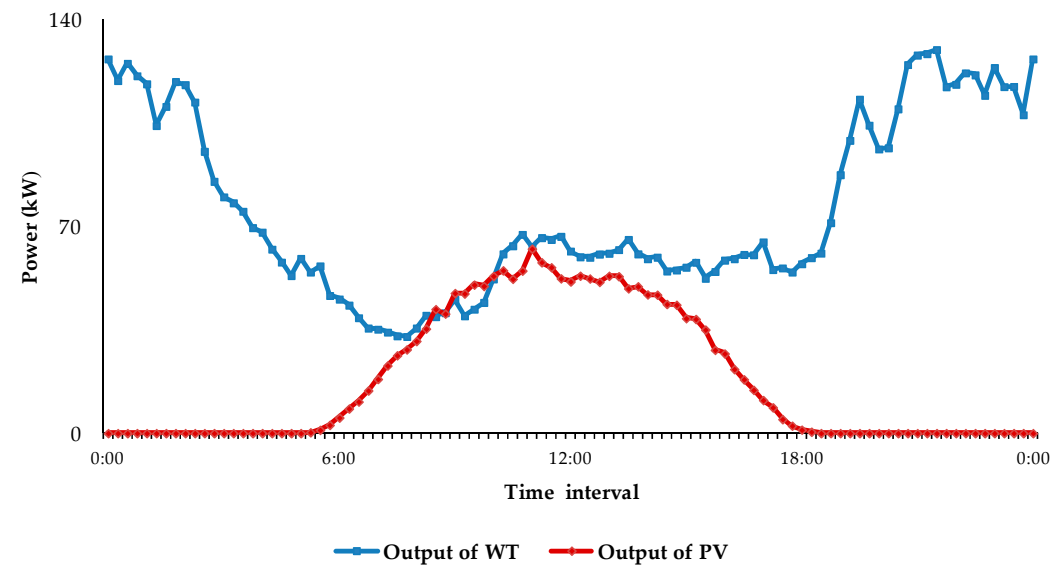

Figure A1. Daily active power output curves of the wind turbine and the PV generator. 
Table A2. Parameters of each EV.

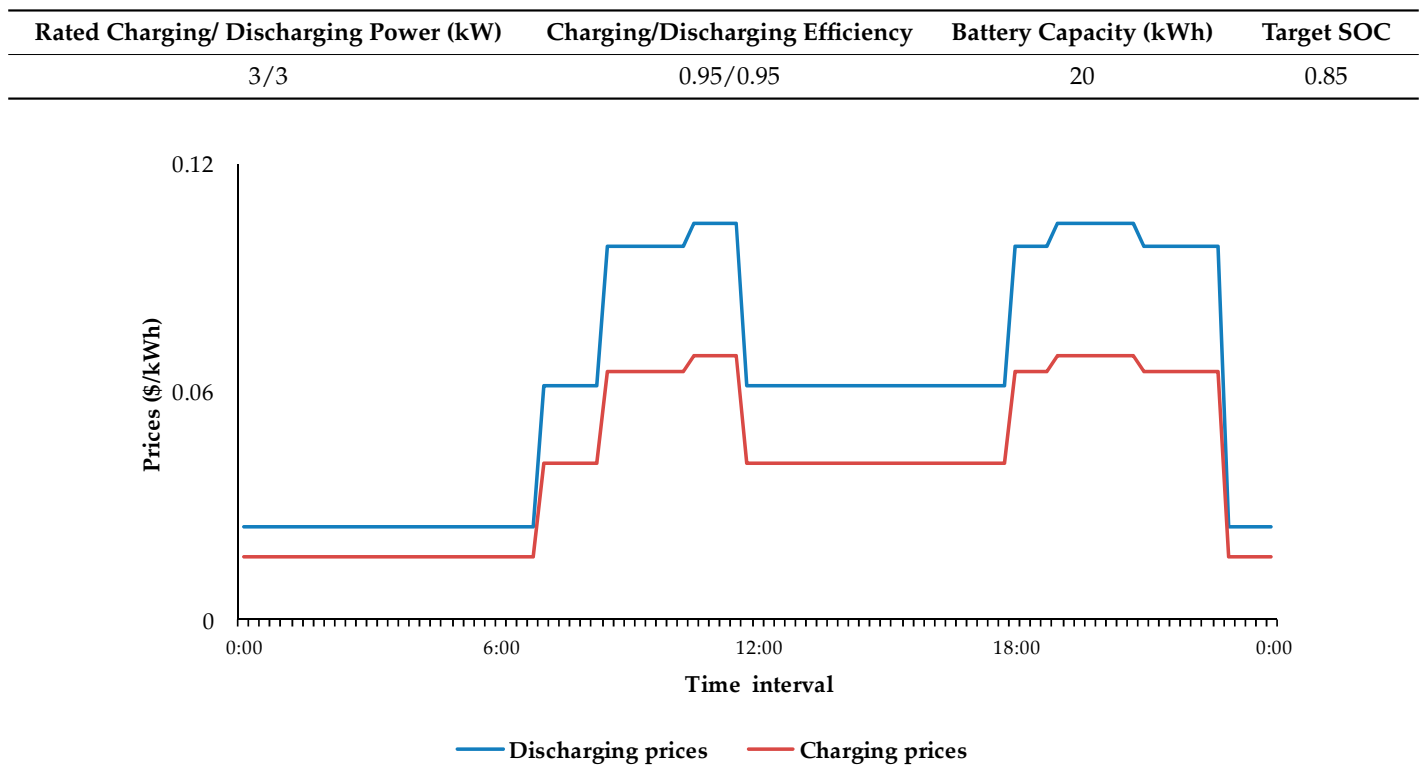

Figure A2. Charging and discharging prices of the EVs.

Table A3. Parameters of the CSACS.

\begin{tabular}{ccccccccc}
\hline$C_{p}^{\max }(\mathbf{k W h})$ & $C_{s}^{\max }(\mathbf{k W h})$ & $C_{r}^{\max }(\mathbf{k W h})$ & $\mu_{\mathrm{p}}$ & $\mu_{\mathrm{s}}$ & $\mu_{\mathrm{r}}$ & $S^{\mathrm{c}, \max }(\mathbf{k W h})$ & $\eta_{\mathrm{s}}$ & $\eta_{\mathrm{r}}$ \\
\hline 6 & 5 & 5 & 5.6 & 0.008 & 0.007 & 26.4 & 0.95 & 0.92 \\
\hline
\end{tabular}

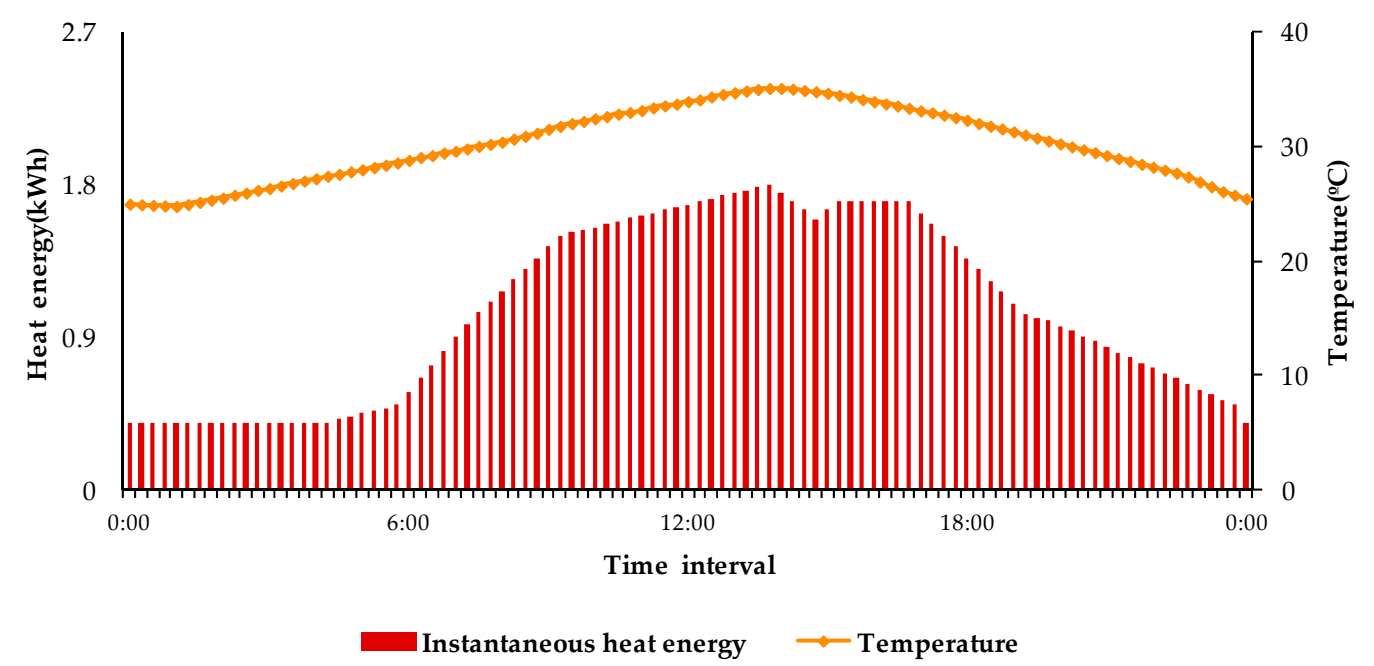

Figure A3. Instantaneous heat energy increment of each intelligent consumer and outdoor temperature.

\section{References}

1. Strasser, T.; Andren, F.; Kathan, J.; Cecati, C.; Buccella, C.; Siano, P.; Leitao, P.; Zhabelova, G.; Vyatkin, V.; Vrba, P.; et al. A review of architectures and concepts for intelligence in future electric energy systems. IEEE Trans. Ind. Electron. 2015, 62, 2424-2438. [CrossRef]

2. Pudjianto, D.; Ramsay, C.; Strbac, G. Virtual power plant and system integration of distributed energy resources. IET Renew. Power Gener. 2007, 1, 10-16. [CrossRef]

3. Asmus, P. Microgrids, virtual power plants and our distributed energy future. Electr. J. 2010, $23,72-82$. [CrossRef] 
4. Howell, S.; Rezgui, Y.; Hippolyte, J.; Jayan, B.; Li, H. Towards the next generation of smart grids: Semantic and holonic multi-agent management of distributed energy resources. Renew. Sustain. Energy Rev. 2017, 77, 193-214. [CrossRef]

5. Qiu, J.; Meng, K.; Zheng, Y.; Dong, Z. Optimal scheduling of distributed energy resources as a virtual power plant in a transactive energy framework. IET Gener. Transm. Distrib. 2017, 11, 3417-3427. [CrossRef]

6. Ruiz, N.; Cobelo, I.; Oyarzabal, J. A direct load control model for virtual power plant management. IEEE Trans. Power Syst. 2009, 24, 959-966. [CrossRef]

7. Pandzic, H.; Morales, J.; Conejo, A.; Kuzle, I. Offering model for a virtual power plant based on stochastic programming. Appl. Energy 2013, 105, 282-292. [CrossRef]

8. Wang, Y.; Ai, X.; Tan, Z.; Yan, L.; Liu, S. Interactive dispatch modes and bidding strategy of multiple virtual power plants based on demand response and game theory. IEEE Trans. Sustain. Energy 2016, 7, 510-519. [CrossRef]

9. European Virtual Fuel Cell Power Plant Management Summary Report. Available online: http:/ / ec.europa. eu/energy/efficiency/industry/doc/euvpp.pdf/ (accessed on 13 August 2013).

10. Pudjianto, D.; Ramsay, C.; Strbac, G.; Dursstewitz, M. The virtual power plant: Enabling integration of distributed generation and demand. FENIX Bull. 2008, 2, 10-16.

11. Dong, W.; Wang, Q.; Yang, L. A coordinated dispatching model for a distribution utility and virtual power plants with wind/photovoltaic/hydro generators. Autom. Electr. Power Syst. 2015, 39, 75-81.

12. He, G.; Chen, Q.; Kang, C.; Xia, Q.; Poolla, K. Cooperation of wind power and battery storage to provide frequency regulation in power markets. IEEE Trans. Power Syst. 2017, 32, 3559-3568. [CrossRef]

13. Vasirani, M.; Kota, R.; Cavalcante, R.; Ossowski, S.; Jennings, N. An agent-based approach to virtual power plants of wind power generators and electric vehicles. IEEE Trans. Smart Grid 2013, 4, 1314-1322. [CrossRef]

14. Giuntoli, M.; Poli, D. Optimized thermal and electrical scheduling of a large scale virtual power plant in the presence of energy storages. IEEE Trans. Smart Grid 2013, 4, 942-955. [CrossRef]

15. Heredia, F.; Rider, M.; Corchero, C. Optimal bidding strategies for thermal and generic programming units in the day-ahead electricity market. IEEE Trans. Power Syst. 2010, 25, 1504-1518. [CrossRef]

16. Bai, H.; Miao, S.; Ran, X.; Ye, C. Optimal dispatch strategy of a virtual power plant containing battery switch stations in a unified electricity market. Energies 2015, 8, 2268-2289. [CrossRef]

17. Luo, F.; Dong, Z.; Meng, K.; Qiu, J.; Yang, J.; Wong, K.P. Short-term operational planning framework for virtual power plants with high renewable penetrations. IET Renew. Power Gener. 2016, 10, 623-633. [CrossRef]

18. Baringo, A.; Baringo, L. A stochastic adaptive robust optimization approach for the offering strategy of a virtual power plant. IEEE Trans. Power Syst. 2017, 32, 3492-3504. [CrossRef]

19. Al-Awami, A.; Amleh, N.; Muqbel, A. Optimal demand response bidding and pricing mechanism with fuzzy optimization: Application for a virtual power plant. IEEE Trans. Ind. Appl. 2017, 53, 5051-5061. [CrossRef]

20. Zhang, G.; Jiang, C.; Wang, X.; Li, B.; Zhu, H. Bidding strategy analysis of virtual power plant considering demand response and uncertainty of renewable energy. IET Gener. Transm. Distrib. 2017, 11, 3268-3277. [CrossRef]

21. Brahman, F.; Honarmand, M.; Jadid, S. Optimal electrical and thermal energy management of a residential energy hub integrating demand response and energy storage system. Energy Build. 2015, 90, 65-75. [CrossRef]

22. Pasetti, M.; Rinaldi, S.; Manerba, D. A virtual power plant architecture for the demand-side management of smart prosumers. Appl. Sci. 2018, 8, 432. [CrossRef]

23. Ji, Z.; Kang, C.; Chen, Q.; Xia, Q.; Jiang, C.; Chen, Z.; Xin, J. Low-carbon power system dispatch incorporating carbon capture power plants. IEEE Trans. Power Syst. 2013, 28, 4615-4623. [CrossRef]

24. Lu, Z.; Lu, C.; Feng, T.; Zhao, H. Carbon dioxide capture and storage planning considering emission trading system for a generation corporation under the emission reduction policy in China. IET Gener. Transm. Distrib. 2015, 9, 43-52. [CrossRef]

25. Tan, Q.; Ding, Y.; Zhang, Y. Optimization model of an efficient collaborative power dispatching system for carbon emissions trading in China. Energies 2017, 10, 1045. [CrossRef]

26. Lu, S.; Wu, Y.; Lou, S.; Yin, X. A model for optimizing spinning reserve requirement of power system under low-carbon economy. IEEE Trans. Sustain. Energy 2014, 5, 1048-1055. [CrossRef]

27. United Nations. The Kyoto Protocol to the United Nations Framework Convention on Climate Change. Available online: http://unfccc.int/resource/docs/convkp/kpeng.pdf (accessed on 1 October 2015). 
28. Lou, S.; Hu, B.; Wu, Y.; Lu, S. Optimal dispatch of power system integrated with large scale photovoltaic generation under carbon trading environment. Autom. Electr. Power Syst. 2014, 38, 91-97.

29. Yao, W.; Zhao, J.; Wen, F.; Xue, Y.; Ledwich, G. A hierarchical decomposition approach for coordinated dispatch of plug-in electric vehicles. IEEE Trans. Power Syst. 2013, 28, 2768-2778. [CrossRef]

30. Koraki, D.; Strunz, K. Wind and solar power integration in electricity markets and distribution networks through service-centric virtual power plants. IEEE Trans. Power Syst. 2018, 33, 473-485. [CrossRef]

31. Karaki, S.; Chedid, R.; Ramadan, R. Probabilistic performance assessment of autonomous solar-wind energy conversion systems. IEEE Trans. Energy Convers. 1999, 14, 766-772. [CrossRef]

32. Mohan, V.; Suresh, R.; Singh, J.; Ongsakul, W.; Madhu, N. Microgrid energy management combining sensitivities, interval and probabilistic uncertainties of renewable generation and loads. IEEE J. Emerg. Sel. Top. Circuits Syst. 2017, 7, 262-270. [CrossRef]

33. Liu, W.; Sun, L.; Lin, Z.; Wen, F. Short-period restoration strategy in isolated electrical islands with intermittent energy sources, energy storage systems and electric vehicles. Autom. Electr. Power Syst. 2015, 39, 49-58.

34. Fanger, P. Thermal Comfort; Danish Technical Press: Copenhagen, Denmark, 1970.

35. International Organization for Standardization. ISO 7730. Moderate Thermal Environment-Determination of $P M V$ and PPD Indices and Specification of the Condition for Thermal Comfort; International Organization for Standardization: Geneva, Switzerland, 2005.

36. Zhang, H.; Wen, F.; Zhang, C.; Meng, J.; Lin, G.; Dang, S. Operation optimization model of home energy hubs considering comfort level of customers. Autom. Electr. Power Syst. 2016, 40, 32-39.

37. Lin, W.; Tu, C.; Tsai, M.; Lo, C. Optimal energy reduction schedules for ice storage air-conditioning systems. Energies 2015, 8, 10504-10521. [CrossRef]

38. Liu, W.; Wu, Q.; Wen, F.; Østergaard, J. Day-ahead congestion management in distribution systems through household demand response and distribution congestion prices. IEEE Trans. Smart Grid 2014, 5, 2739-2747. [CrossRef]

39. Ma, Y.; Saha, S.; Miller, W.; Guan, L. Parametric analysis of design parameter effects on the performance of a solar desiccant evaporative cooling system in Brisbane, Australia. Energies 2017, 10, 849. [CrossRef]

40. Qi, F.; Wen, F.; Liu, X.; Salam, M. A residential energy hub model with a concentrating solar power plant and electric vehicles. Energies 2017, 10, 1159. [CrossRef]

41. Luo, F.; Zhao, J.; Dong, Z.; Tong, X.; Chen, Y.; Yang, H.; Zhang, H. Optimal dispatch of air conditioner loads in Southern China region by direct load control. IEEE Trans. Smart Grid 2016, 7, 439-450. [CrossRef]

42. Arslan, O.; Karasan, O. Cost and emission impacts of virtual power plant formation in plug-in hybrid electric vehicle penetrated networks. Energy 2013, 60, 116-124. [CrossRef] 